\title{
Hip muscle power recovery after hip replacement using anterior-based muscle-sparing approach in elderly femoral neck fracture: a prospective study in 40 patients
}

This article was published in the following Dove Press journal:

Orthopedic Research and Reviews

\section{Kulapat Chulsomlee ${ }^{1,2, *}$ \\ Paphon Sa-ngasoongsongl,* Noratep Kulachote' Norachart Sirisreetreerux' Panithan Tuntiyatorn ${ }^{1,2}$ Satetha Vasaruchapong' Sorawut Thamyongkit ${ }^{1,2}$ Chavarat Jarungvittayakon' Siwadol Wongsak' Viroj Kawinwonggowit ${ }^{\prime}$ \\ 'Department of Orthopedics, Faculty of Medicine Ramathibodi Hospital, Mahidol University, Bangkok, Thailand; ${ }^{2}$ Faculty of Medicine Ramathibodi Hospital, Chakri Naruebodindra Medical Institute, Mahidol University, Bangkok, Thailand}

*These authors contributed equally to this work
Correspondence: Paphon

Sa-ngasoongsong

Department of Orthopedics, Faculty of Medicine Ramathibodi Hospital, Mahidol University, 270, Rama VI Road, Ratchathewi, Bangkok 10400, Thailand

Tel +6622011589

Fax +6622011599

Email paphonortho@gmail.com
Introduction: The early rehabilitation and mobilization after hip arthroplasty (HA) in elderly femoral neck fracture (FNF) patients significantly reduces the postoperative morbidity and mortality. The direct anterior approach (DAA) without the muscle detachment has been shown to improve the early postoperative functional outcomes in coxarthrosis patients. However, the application of DAA on elderly FNF and the most suitable surgical technique have rarely been investigated. This study aimed to report the short-term outcome after our anterior-based musclesparing approach (ABMS) in elderly FNF.

Materials and methods: A prospective study, in 40 elderly unilateral FNF patients who underwent HA with ABMS, was conducted. The primary outcomes were hip flexion and abduction power at each follow-up period. The contralateral muscle power, measured at 3 and 6 months, was used as the control value. The perioperative data and complications were recorded.

Results: Thirty-two patients underwent bipolar hemiarthroplasty (BHA), while eight other patients received total hip arthroplasty (THA). The hip abduction power returned to control value at 6 weeks $(99.0 \% \pm 6.1 \% ; 95 \% \mathrm{CI}: 86.1-111.8)$. The hip flexion power returned to control at 3 months (108.5\% $\pm 5.6 \%, 95 \%$ CI: 96.8-120.2). No iatrogenic nerve injury was found. The intraoperative femoral fracture (IFF) was found in 7 patients $(17.5 \%)$, and was significantly related to the early period of learning skill (first 11 cases; $p<0.01$ ). BHA had nonsignificant higher IFF than THA ( 8 vs. $0 ; p=0.31$ ).

Conclusion: After ABMS, the hip muscle could recover to the baseline value within 3 months without iatrogenic nerve injury. The ABMS-related complication, which was IFF, could be significantly improved with the learning skill. The adequate posterior soft tissue release and gentle manipulation of the hip joint might play important roles for IFF prevention. BHA might relate to higher risk of IFF because of difficult reduction from large femoral head diameter.

Keywords: direct anterior approach, muscle-sparing hip approach, femoral neck fracture, hip muscle power, functional outcome, complications, hip approach-related complication

\section{Introduction}

The osteoporotic femoral neck fracture (FNF) is one of the most common fractures in elderly. ${ }^{1}$ It is clear that early hip surgery and encouraging early postoperative mobilization have positively affected the mortality and morbidity. The early mobilization can reduce the chance of developing chest infection, urinary tract infection, pressure sore, deep vein thrombosis, and muscle wasting. ${ }^{2-4}$ Regarding the early mobilization in postoperative period, many perioperative factors could be influenced such as postoperative 
pain control and the less invasive surgical approach. Recent studies showed that the anterior-based muscle-sparing approach (ABMS), for example, direct anterior approach (DAA), which dissects intermuscularly without the need of abductor muscle detachment, had potential benefits in early patient-reported pain, narcotic consumption, functional outcomes, shorter length of hospital stay, and dislocation. ${ }^{5}$ Moreover, ABMS showed improvement in a larger number of gait parameters than the anterolateral approach. ${ }^{6-8}$ From those reasons, the ABMS should have better hip muscle and functional recovery. However, to the best of our knowledge, no previous studies had demonstrated the effect of this ABMS on hip muscle power recovery after hip replacement surgery in elderly FNF patients.

The aim of this study was to present the recovery of hip muscular power at each period compared with the normal contralateral hip. Contrary to other literatures, ${ }^{8-12}$ the postoperative hip muscular assessment in this study was measured in the bilateral normal hip subject. Therefore, this eliminates the effect of preexisting hip muscular hypotrophy and increases the reliability of the muscular recovery result after ABMS approach. Moreover, author also describes the functional outcomes, complications, and method to decrease the intraoperative complications of ABMS in osteoporotic FNF.

\section{Materials and methods}

This study was a prospective study and was approved by our Institutional Review Board (Protocol number: 06-59-07), based on the Declaration of Helsinki. Each patient was informed that data from the case would be submitted for publication, and gave their consent.

The elderly patients who suffered from low-energy FNF were recruited during January 2016 to January 2017. The inclusion criteria were 1) age over 50 years; 2) displaced FNF requiring joint replacement; 3) independent ambulation without gait aid prior to fracture; 4) absence of neuromuscular disorder; and 5) bilateral normal hip joint. The exclusion criteria were 1) contraindication to surgery; 2) presence of neuromuscular disease and cognitive impairment; 3) present of hip disease prior to injury, either unilateral or bilateral; and 4) prior hip surgery. Patients who had active lifestyle were treated by total hip arthroplasty (THA) while advanced-age patients who had sedentary lifestyle were treated by bipolar hemiarthroplasty (BHA). Decision to use cementless or cemented implant depended on bone quality. The operations were performed by welltrained joint replacement surgeon $(\mathrm{KC})$ and experienced trauma surgeon (PS).
All patients were treated with hip replacement through ABMS and were placed in supine position on extension surgical table. The ipsilateral shoulder was in $90^{\circ}$ forward flexion and adduction position to increase working space during operation. Prophylactic antibiotic was given $30 \mathrm{~min}$ before operation. The operative leg was prepared in sterile fashion.

All implants were manufactured by Depuy-Synthes Company (Warsaw, IN, USA). The Corail-cementless, Corailcemented, and C-stem design were selected depending on degree of osteoporosis and bony geometry. Self-centering bipolar head with $28 \mathrm{~mm}$ inner-femoral head diameter and the cementless PINNACLE acetabulum cup were used in hemiarthroplasty and THA, respectively. PALACOS bone cement was used if needed.

The incision was made at anterolateral aspect of hip, -3 fingerbreadths lateral from anterior superior iliac spine (ASIS). The incision started at a few centimeters above tip of greater trochanter (GT) and extended distally about 8-10 $\mathrm{cm}$. To avoid the lateral femoral cutaneous nerve injury, the iliotibial band (ITB) was incised longitudinally at about $1 \mathrm{~cm}$ posterior to muscle part of tensor fascia lata (TFL). Hip capsule was exposed through the intermuscular plane between rectus femoris (medially) and gluteus medius muscle (laterally). The lateral femoral circumflex artery was coagulated. The reflected tendon insertion of the rectus femoris was released. The anterolateral joint capsule could be done either capsulotomy or capsulectomy depending on the surgical exposure. If capsulotomy was done, the incised capsule was later repaired. Fracture site and the remaining femoral neck were identified. The osteotomy of the femoral neck was done using oscillating saw. The femoral head was extracted with a corkscrew. Regarding THA, the acetabulum rim was $360^{\circ}$ exposed. The acetabulum was under-reamed $1 \mathrm{~mm}$ to achieve press-fit under fluoroscopic guidance. The final cup was inserted. It was author's preference to insert at least 1 screw. To prepare the proximal femur (also in BHA), the leg part of the surgical extension was dropped to take the hip in extension position. The affected leg was placed in figure of four positions (extension, adduction, and external rotation of the hip) to expose the proximal femur. The Cobra retractor was applied at the posterior cortex of proximal femur and underneath the GT. The posterolateral joint capsule was released until it adequately brought the proximal femur upward and lateral. The femoral canal rasping and insertion of the trial femoral implant were done with caution. In case of BHA, the hip was reduced without putting in the trial bipolar head to decrease the intraoperative proximal femoral fracture (IFF). The longitudinal traction was applied under 
fluoroscopic guidance. If the tip of the trial neck could be pulled down to the radiographic U-sign (Figure 1), then it was considered to be reducible. The length of bipolar head was then later adjusted after final femoral stem insertion. If the trial femoral implant fitted tightly and was stable, cementless implant was used, otherwise a medullary distal plug and a cemented implant were put in. The intraoperative fluoroscopic evaluation was always performed to check the trial implant position before applied as the final implant. Drain was applied. The tensor fascia, subcutaneous tissue, and skin were repaired layer by layer.

The drain was removed within 48 hours. The patient was instructed to mobilize with full-weight bearing on the second or third postoperative day depending on the patient's condition. The follow-up controls were at second and sixth weeks, 3 and 6 months after surgery.

The primary outcome was hip abduction and flexion muscle strength measured by hand-held dynamometer (Microfet2, Hoggan Health Industry, USA). Secondary outcomes were modified timed up and go test (mTUGT), Western Ontario and McMaster Universities Osteoarthritis Index (WOMAC) hip score, Harris hip score (HHS), and the ABMS-related complications including IFF (for instance, GT fracture and femoral calcar fracture), the

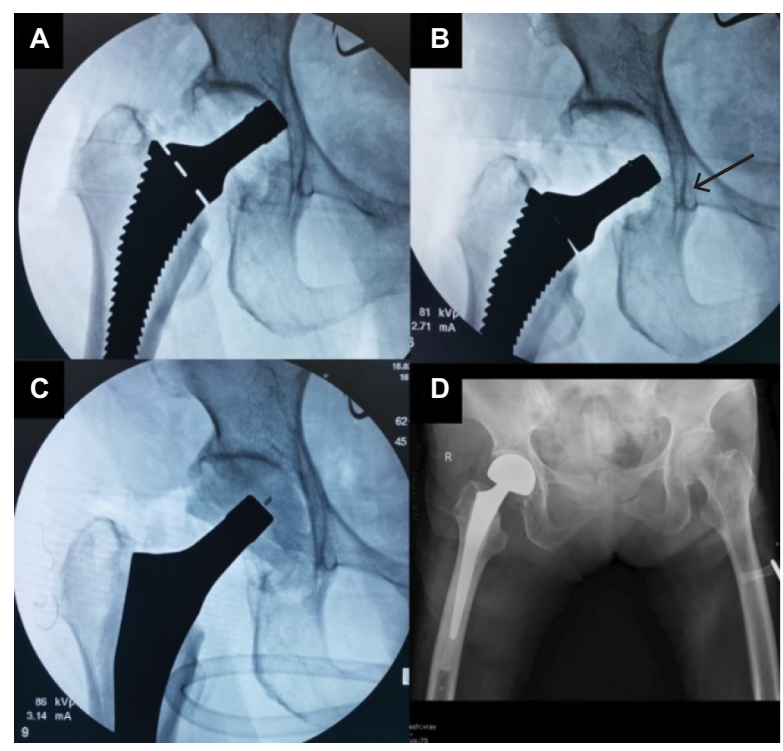

Figure I Demonstrates the authors' preferred technique to prevent the intraoperative femoral fracture during dislocation reduction of the trial component. Notes: The trial neck was inserted and reduced the joint without putting in the trial bipolar head (A). Under fluoroscopic guidance, the longitudinal traction force was applied. If the tip of trial neck can be pulled down to the radiographic $U$ level (B, black arrow), then it was considered to be reducible in case of presence of the bipolar head. The trial bipolar head was then inserted after the final femoral component application (C), and leg length can be adjusted at this step. The postoperative radiograph (D) shows the equal leg length. heterotrophic ossification (HO), postoperative dislocation, and infection.

The hip abduction power was measured in standing or lateral decubitus position, depending on patient's ability. The hand-held dynamometer was applied at just above the knee joint. Patient was asked to abduct hip against the examiner as much as possible. The peak muscle strength was recorded (newton). The hip flexion muscle strength was done in the exact method as the hip abduction measurement. Because of the global muscular weakness after THA, ${ }^{13}$ which resolved within 1 month after operation, the author used the average value of nonoperative hip flexion and abduction strength measured at 3 and 6 months postoperatively as the control value. The muscular strength of the operative hip was presented as the percentage change from the control value. The mTUGT in this study was different from the original TUGT. ${ }^{14}$ The postoperative elderly patients had high risk of falling during walking and turning around. To provide safety for the patients, author made some modification of the original TUGT and defined mTUGT as the time spent from chairraise and walk straight for 3 meters. Range of motion was measured clinically by goniometer. The hip muscle strength and mTUGT were measured at the discharge date, second and sixth weeks, and 3 and 6 months postoperatively. The WOMAC and HSS were evaluated at second and sixth weeks, and 3 and 6 months postoperatively.

Perioperative data including the demographic data, preoperative laboratory assessment, intraoperative information, and postoperative in-admission data were collected. Surgical approach-related complications including femoral calcar fracture, GT fracture, and amount of abductor muscle injury were recorded. The total hemoglobin loss was calculated from the difference between preoperative hemoglobin and the third day postoperative hemoglobin plus the total units of pack red cell (PRC) transfusion. We estimated that 1 unit of PRC transfusion was equivalent to $1 \mathrm{~g} / \mathrm{dL}$ of hemoglobin loss.

The both hips anterioposterior-standing radiograph was taken postoperatively at 3 months. To calculate the leg length discrepancy (LLD), we used the method described by Meermans. ${ }^{15}$ Radiographic assessment of the LLD was performed by using the bi-ischial line (BI) as a pelvic reference. The BI was drawn passing through the femoral reference (lesser trochanter, LT). The distance between BI-LT landmarks was calculated. The difference in distance between both sides was used to assess LLD. The Brooker's classification ${ }^{16}$ was used to classify the grading of $\mathrm{HO}$.

Statistical analyses were performed using the statistical program STATA (version 12, Stata Corp., College Station, 
TX, USA). We calculated distribution of variables using mean and SD for normally distributed data, and median and interquartile ranges for non-normally distributed data. The continuous data were calculated by unpaired $t$-test. The categorical data were calculated by chi-square or Fisher's exact test as appropriate. The repeated-measurement analysis of variance was used to determine statistical difference in the muscle strength recovery, and WOMAC, HSS, and TUGT were compared between each follow-up period.

\section{Institutional Review Board statement}

This study was reviewed and approved by the Ethical Clearance Committee on Human Rights to Research Including Human Subjects, Faculty of Medicine Ramathibodi Hospital, Mahidol University (Protocol number: 06-59-07).

\section{Informed consent statement}

All patients provided written informed consent for the publication of the case details.

\section{Results}

Forty patients were recruited into this study (Table 1). The mean age was 75 years (range 53-98 years). Six of them (15\%) were male and 34 patients $(85 \%)$ were female. Thirty-two patients (80\%) underwent BHA while eight other patients $(20 \%)$ received THA. The mean operative time (Table 2) was $101 \pm 25 \mathrm{~min}$. The mean total hemoglobin loss was $2.7 \pm 2.2 \mathrm{~g} / \mathrm{dL}$ requiring on average $1.2 \pm 1.3$ units of PRC transfusion. The mean length of hospital stay was $7 \pm 5$ days. One patient $(2.5 \%)$ died at third day postoperatively because

Table I Demographic data

\begin{tabular}{|c|c|}
\hline & $n=40$ \\
\hline Age $e^{a}$ (years) & $75 \pm 11$ \\
\hline Female $^{b}$ & $34(85 \%)$ \\
\hline Length of hospital stay ${ }^{\mathrm{a}}$ (days) & $7 \pm 5$ \\
\hline Length of postoperative hospital stay ${ }^{2}$ (days) & $4 \pm 3$ \\
\hline Hemoglobin $^{a}(g / d L)$ & $11.7 \pm 1.6$ \\
\hline Albumin $^{\mathrm{a}}(\mathrm{g} / \mathrm{dL})$ & $32.8 \pm 5.0$ \\
\hline Creatinine clearance ${ }^{a}\left(\mathrm{~mL} / \mathrm{min} / \mathrm{m}^{2}\right)$ & $69.6 \pm 23.5$ \\
\hline $\mathrm{INR}^{\mathrm{a}}$ & $1.04 \pm 0.19$ \\
\hline \multicolumn{2}{|l|}{ Operation type ${ }^{b}$} \\
\hline Cementless BHA & $6(15 \%)$ \\
\hline Cemented BHA & $26(65 \%)$ \\
\hline Cementless THA & $6(15 \%)$ \\
\hline Cemented THA & $2(5 \%)$ \\
\hline 6-month mortality rate $(\%)$ & I (2.5\%) \\
\hline
\end{tabular}

Notes: ${ }^{a}$ alues presented as mean \pm SD. ${ }^{b}$ Values presented as number of cases (percentage).

Abbreviations: BHA, bipolar hemiarthroplasty; INR; international normalized ratio; THA, total hip arthroplasty.
Table 2 Perioperative data

\begin{tabular}{lllll}
\hline Factors $^{\mathbf{a}}$ & $\begin{array}{l}\text { Total } \\
(\mathbf{n = 4 0})\end{array}$ & $\begin{array}{l}\text { First II } \\
\text { cases }\end{array}$ & $\begin{array}{l}\text { Next 29 } \\
\text { cases }\end{array}$ & p-value \\
\hline Operative time (minutes) & $101 \pm 25$ & $120 \pm 28$ & $94 \pm 27$ & $0.0 I^{*}$ \\
Estimated blood loss (mL) & $436 \pm 202$ & $432 \pm 226$ & $438 \pm 192$ & 0.94 \\
Total hemoglobin loss (g/dL) & $2.7 \pm 2.2$ & $2.8 \pm 1.2$ & $2.7 \pm 2.5$ & 0.93 \\
PRC transfusion (units) & $1.2 \pm 1.3$ & $1.7 \pm 1.6$ & $0.9 \pm 1.2$ & 0.16 \\
\hline
\end{tabular}

Notes: ${ }^{a}$ Values presented as mean \pm SD. *Significantly different with $p<0.05$ (calculated by unpaired $t$-test).

Abbreviation: PRC, pack red cell.

Table 3 The anterior-based muscle-sparing hip approach-related complications

\begin{tabular}{lllll}
\hline Complication $^{\mathbf{a}}$ & $\mathbf{n = 4 0}$ & $\begin{array}{l}\text { First II } \\
\text { cases }\end{array}$ & $\begin{array}{l}\text { Next 29 } \\
\text { cases }\end{array}$ & -value \\
\hline Femoral calcar crack & 4 & 3 & $\mathrm{I}$ & \\
Greater trochanteric fracture & 3 & 3 & 0 & \\
Dislocation & $\mathrm{I}$ & $\mathrm{I}$ & 0 & \\
Overall complications & 8 & 7 & $\mathrm{I}$ & $<0.0 \mathrm{I}^{*}$ \\
\hline
\end{tabular}

Notes: a ${ }^{V}$ alue presented as number of cases having that complication. *Significant difference with $p<0.05$ (calculated by chi-square test).

of acute myocardial infarction. All patients were followed up for at least 6 months postoperatively.

The overall ABMS-related complications in this study were $20 \%(n=8$, femoral calcar crack 4 , GT fracture 3, and postoperative hip dislocation 1; Table 3). The femoral calcar cracks were treated by intraoperative wiring. All GT fractures were minimally displaced and treated with closed observation. The postoperative hip dislocation was found at 2 weeks postoperatively. No iatrogenic lateral femoral cutaneous nerve injury was found. Neither periprosthetic joint infection nor aseptic loosening was found during the follow-up period.

The mean postoperative hip flexion power at discharge was $40.4 \% \pm 5.0 \%$ (Figure 2 ). After operation, the postoperative hip flexion power was statistically improved at all follow-up period points compared with those at discharge period $(67.7 \% \pm 6.3 \%$ at 2 weeks, $89.2 \% \pm 4.5 \%$ at 6 weeks, $108.5 \% \pm 5.6 \%$ at 3 months, and $97.5 \% \pm 3.7 \%$ at 6 months, $p<0.05$ for all). Concerning the hip abduction power, the mean hip abduction power at discharge was $54.9 \% \pm 6.0 \%$. The postoperative hip abduction strength was significantly improved at all follow-up periods compared with the discharge period $(79.0 \% \pm 6.6 \%$ at 2 weeks, $99.0 \% \pm 6.1 \%$ at 6 weeks, $103.7 \% \pm 4.0 \%$ at 3 months, and $114.3 \% \pm 3.7 \%$ at 6 months, $p<0.05$ for all).

The mean mTUGT at discharge was 50.9 \pm 6.5 seconds (Figure 3A). There was a significantly faster TUGT at all follow-up periods compared with the discharge period $(22.7 \pm 2.2$ at 2 weeks, $14.9 \pm 2.0$ at 6 weeks, $9.2 \pm 1.5$ at 3 months, and $8.9 \pm 1.4$ at 6 months, $p<0.05$ for all). 


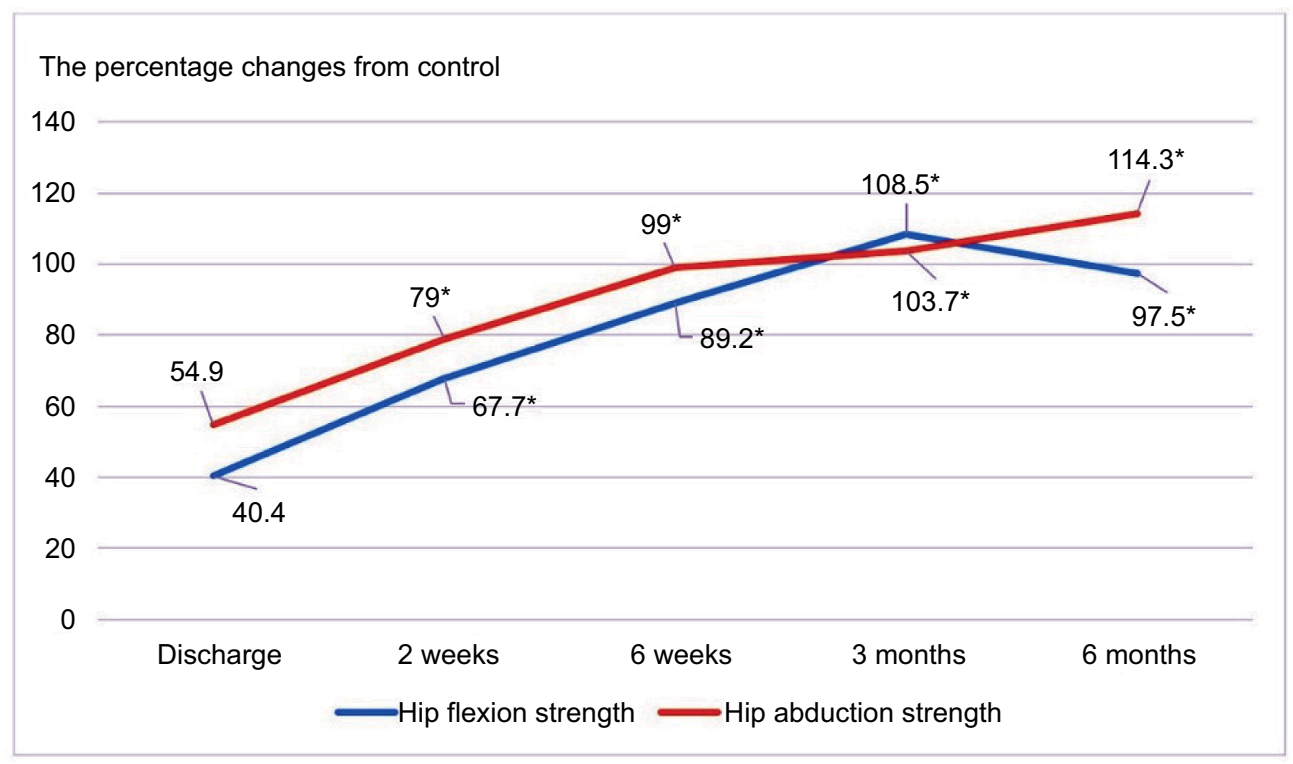

Figure 2 Hip muscle power changes after operation.

Notes: The hip muscle power was presented as percentage compared with the contralateral hip muscle power. The asterisk $(*)$ indicates that the presented value was significantly improved compared with the value at the discharge with $p<0.05$. The hip abduction and flexion power were returned to baseline (contralateral side) at 6 weeks and 3 months after surgery (hip abduction power at 6 weeks: $99.0 \% \pm 6.1 \%$; $95 \% \mathrm{Cl}: 86 . \mathrm{I}-\mathrm{II}$ I.8, and hip flexion power at 3 months: $108.5 \% \pm 5.6 \%$; $95 \% \mathrm{Cl}$ : 96.8-120.2).
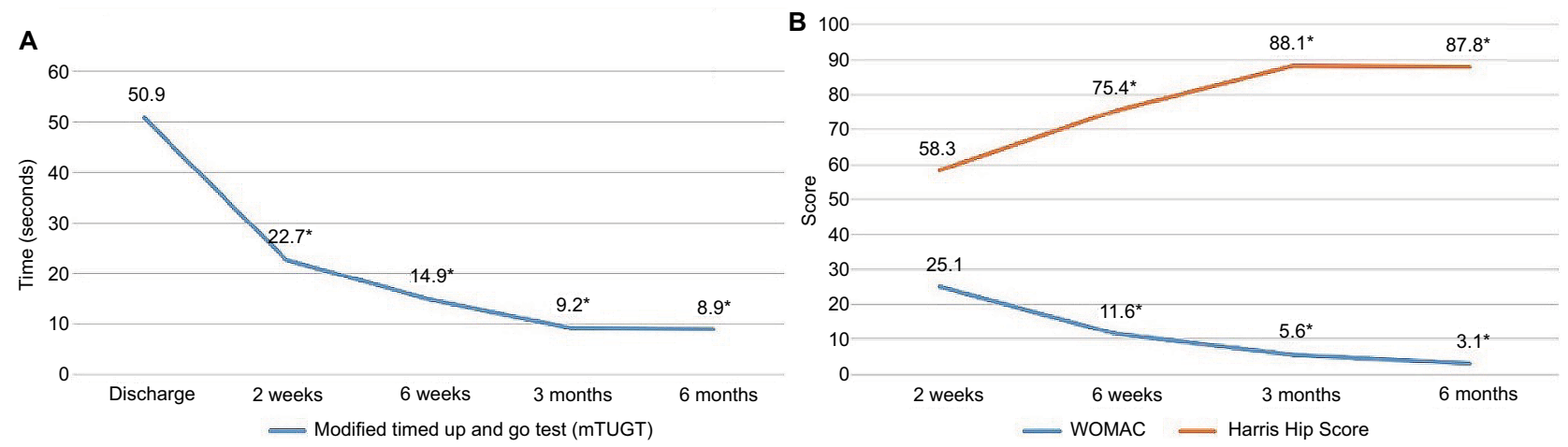

Figure 3 Postoperative outcome as the modified timed up and go test $(\mathbf{A})$ and functional hip score (B; WOMAC and Harris hip score) after operation. Note: The asterisk $(*)$ indicates that the presented value was significantly better than the baseline value with $p<0.05$.

Abbreviation: WOMAC, Western Ontario and McMaster Universities Osteoarthritis Index.

The mean WOMAC score and HSS at 2 weeks were $25.0 \pm 2.5$ and $58.3 \pm 2.3$, respectively (Figure 3B). During the follow-up period, the WOMAC score and HSS were statistically improved at all follow-up periods ( $11.6 \pm 1.8$ at 6 weeks, $5.6 \pm 1.1$ at 3 months, and $3.1 \pm 0.8$ at 6 months for WOMAC; $75.4 \pm 2.4$ at 6 weeks, $88.1 \pm 1.6$ at 3 months, and $87.8 \pm 2.0$ at 6 months for HSS, $p<0.05$ for all).

The range of motion (Table 4) was nonsignificantly increased from the second week to the sixth month. At sixth month follow-up, the mean flexion was $130 \pm 8^{\circ}, 53 \pm 5^{\circ}$ for abduction, $56 \pm 6^{\circ}$ for external rotation, and $21 \pm 7^{\circ}$ for internal rotation.

The mean LLD was $5.3 \pm 5.9 \mathrm{~mm}$ (Table 5). Three patients (7.5\%) had LLD $>1 \mathrm{~cm}(11.3-16.5 \mathrm{~mm})$. Regarding the HO,
Table 4 Hip range of motion

\begin{tabular}{lllll}
\hline $\begin{array}{l}\text { Postoperative } \\
\text { period }\end{array}$ & Flexion & Abduction & $\begin{array}{l}\text { External } \\
\text { rotation }\end{array}$ & $\begin{array}{l}\text { Internal } \\
\text { rotation }\end{array}$ \\
\hline 2 weeks & $115 \pm 13$ & $43 \pm 9$ & $39 \pm 7$ & $17 \pm 5$ \\
6 weeks & $117 \pm 12$ & $47 \pm 7$ & $48 \pm 8$ & $18 \pm 5$ \\
3 months & $127 \pm 7$ & $50 \pm 3$ & $50 \pm 4$ & $20 \pm 5$ \\
6 months & $130 \pm 8$ & $53 \pm 5$ & $56 \pm 6$ & $21 \pm 7$ \\
\hline
\end{tabular}

Note: Values presented as mean \pm SD.

there was no $\mathrm{HO}$ in 33 patients $(82.5 \%)$. Six patients $(15 \%)$ had HO grade 1 and one patient (2.5\%) had HO grade 3.

Regarding the evaluation of the effect from learning skill and ABMS-related complications, we found that the ABMSrelated complications in the first 11 cases was significantly 
Table 5 The 3-month radiograph evaluation of both hips standing

\begin{tabular}{lllll}
\hline & $\mathbf{n = 4 0}$ & $\begin{array}{l}\text { First I I } \\
\text { cases }\end{array}$ & $\begin{array}{l}\text { Next 29 } \\
\text { cases }\end{array}$ & p-value \\
\hline LLD $>$ I cm & $3(7.5 \%)$ & I (9.1\%) & $2(6.9 \%)$ & I.00 \\
Heterotrophic ossification & & & & \\
Grade I & 6 & 2 & 4 & \\
Grade 2 & 0 & 0 & 0 & \\
Grade 3 & $\mathrm{I}$ & $\mathrm{I}$ & 0 & $0.04 *$ \\
Grade 4 & 0 & 0 & 0 & \\
\hline
\end{tabular}

Notes: ${ }^{a}$ Values presented as number of cases (percentage). *Significant difference with $p<0.05$ (calculated by Fisher's exact test or chi-square test).

Abbreviation: LLD; leg length discrepancy.

higher than those in the later 29 cases $(63.6 \%$ vs. $3.4 \%$; $p<0.001$; Tables 2 and 5). The operative time was significantly longer in the first 11 cases $(120 \pm 28.2 \mathrm{~min}$ vs. $93.6 \pm 27.1 \mathrm{~min}$; $p=0.01$ ). Furthermore, the incidence of $\mathrm{HO}$ was significantly higher in the first 11 cases $(27.3 \%$ vs. $13.8 \%, p=0.04)$. One patient in the first 11 cases had $\mathrm{HO}$ grade 3 , while others had $\mathrm{HO}$ grade 1 . However, the estimated blood loss, total hemoglobin loss, PRC transfusion, and the LLD were not significantly different.

Regarding the postoperative medical complications, four patients $(10 \%)$ had in-admission postoperative cardiovascular complications. One patient died from acute myocardial infarction at postoperative day 3 , while three other patients had congestive heart failure treated with intravenous diuretic medication. All patients with congestive heart failure could be discharged from hospital within 13 days after operation (4-13 days). Three patients had delirium, which required psychological consultation. There was neither deep vein thrombosis nor pulmonary embolism in our series.

\section{Discussion}

At the present, the DAA has gained popularity among orthopedic surgeons. There were several studies that described the benefits and drawbacks of this surgical technique. The main advantages were abductor muscle preservation, faster rehabilitation, pain reduction, and lower dislocation rate. ${ }^{5,17-20}$ On the contrary, the disadvantages were surgical technique difficulty and potentially higher IFF. ${ }^{21,22}$ Rudiger et al ${ }^{23}$ reported significant poorer functional result in patients with IFF. To the best of our knowledge, there was no literature that described the hip muscle recovery in elderly FNF using DAA approach.

The surgical technique that we used in all cases was ABMS. The change between ABMS and standard $\mathrm{DAA}^{24}$ was the more lateral skin incision and the longitudinal incision of the ITB instead of TFL-sartorius muscle intermuscularly splitted. The advantage of this different approach over standard DAA was to reduce the risk of iatrogenic lateral femoral cutaneous nerve injury and feasible surgical scar for future revision surgery. However, we believe that our study can represent the result of DAA in FNF, because both techniques preserved hip abduction muscle, required posterior capsular release, lifting the GT upward, and used exactly the same instruments.

The DAA showed faster hip muscle recovery than the standard anterolateral approach, which could take up to several years to regain back to age-matched value. ${ }^{8-11}$ Winther et a ${ }^{12}$ reported that the hip abduction and flexion strength after DAA and PL approach had returned to preoperative value at 6 weeks after surgery but were still $15 \%$ and $18 \%$ less than the nonoperated side at 3 months, respectively. They concluded that this could be the result of the preexisting hip muscle atrophy in coxarthrosis patients before THA. In contrast, the present study population was bilaterally normal hip joint prior to surgery, independent ambulation without gait aid before fracture, and absence of neuromuscular disorder. Therefore, the present study does not have the negative effect of the preexisting hip muscle atrophy and could represent the actual value of hip muscle recovery after muscle-sparing approach.

Concerning the muscle injury, the author found that $89 \%$ of patients had gluteus minimus injury $0.97 \mathrm{~cm}$ on average without the gluteus medius muscle injury. The gluteus minimus tendon has two insertions including the anterior joint capsule and the lateral ridge to the anterior triangular area of the GT. ${ }^{25}$ Thus, it was easily damaged during the capsulectomy, the posterior soft tissue release, and the femoral canal preparation step. Corresponding to Amanatullah et $\mathrm{al}^{26}$ who conducted the THA via DAA in eight fresh cadavers, they reported that DAA causes significantly greater gluteus minimus damage than direct lateral approach. However, the gluteus minimus damage after ABMS probably has little effect on the daily activity, and the muscular strength recovery because the functional hip score showed significant improvement and the muscular strength returned to the nonoperated side within 6-12 weeks after surgery.

The HSS and WOMAC hip score were significantly improved during each visit. The functional hip score after ABMS at 6 months was comparable to the other standard approach. ${ }^{27-32}$ Our findings suggest that the ABMS approach did not show the superior result in terms of the hip function score at 6 months when compared with the other approach.

The total operative time, the ABMS-related complications, and the incidence of $\mathrm{HO}$ were significantly worse in the first 11 cases. On the contrary, the DAA approach may 
require up to 46-100 cases for learning skill ${ }^{21,33,34}$ depending on initial experience of the surgeon. The ABMS approach was probably more suitable for initial experience surgeon than DAA because of this lower learning skill effect.

The overall IFF incidence in our study was $17.5 \%$, which was higher than that in the previous published studies. ${ }^{17,35,36}$ As previously expected, the higher IFF could be the result of soft osteoporotic bone combined with the minimal invasive approach. Nevertheless, the incidence of IFF dropped to 3.4\% after the first 11 cases were excluded, which was equal to the DAA in the normal bone. Beside the learning skill effect, BHA had nonsignificantly higher IFF than THA (25\% vs. $0 \% ; p=0.31$ ). This could be the result of larger bipolar head in BHA than the femoral head in THA. The author found that most of the femoral calcar fractures occurred during reduction dislocation of the trial bipolar head. In the osteoporotic bone, the femoral trial stem is usually not fixed enough to tolerate the powerful rotational force, which happens during reduction dislocation of the large bipolar head through the narrowed space. This finally causes femoral calcar fracture. The author recommends to always use the fluoroscopic imaging to evaluate the femoral stem position without putting in the trial bipolar head as previously described (Figure 1). Considering the GT fracture, the Cobra retractor must be applied firmly on the posterior aspect of GT. The posterior capsule must be adequately released before lifting the GT upward.

The author noticed that two patients with the fan-shaped pelvic morphology associated with low ASIS-GT distance (Figure 4) trend required longer operative time than usual ( $115 \pm 5$ vs. $92 \pm 19$ min; $p$-value=0.06). Regarding the ABMS surgical technique, the anterior space between ASIS-GT was

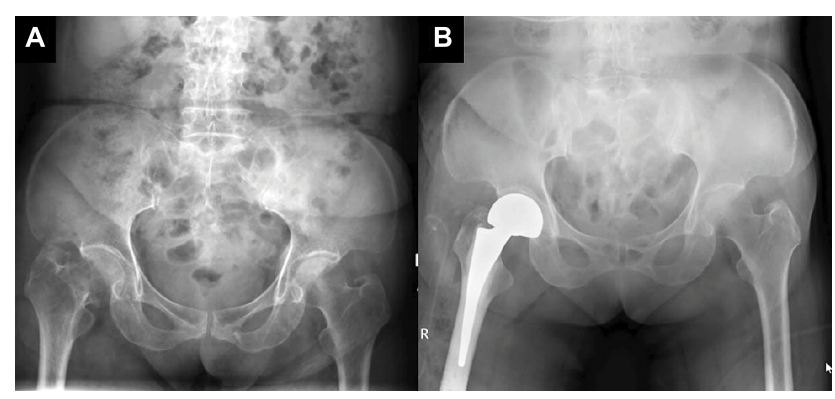

Figure 4 The radiograph shows the fan-shaped pelvic morphology, before $(\mathbf{A})$ and after (B) the operation.

Notes: The distance from the anterior superior iliac spine to the greater trochanter was very low. This indicated that the working space in ABMS was extremely limited. The total operative time was nonsignificantly longer than usual (1 I5 \pm 5 vs. $92 \pm 19$ min; $p$-value=0.06). There was a potential higher abduction muscle injury in this type of pelvic morphology. However, the amount of hemoglobin loss and pack red cell transfusion were not different. The authors recommend the use of the other conventional approach instead of ABMS.

Abbreviation: $\mathrm{ABMS}$, anterior-based muscle-sparing approach. necessary in the femoral preparation step. Extensive posterior soft tissue releases and increasing adduction angle on the operative leg to bring the proximal femur more to the lateral direction were often required. In theory, the risk of abductor muscle injury and postoperative dislocation should be higher. However, the author did not find those complications in this study. In case of low ASIS-GT distance, the author recommends the use of anterolateral or posterior approach instead of ABMS.

Regarding the dislocation rate, there was one patient $(2.5 \%)$ with postoperative hip dislocation. The possible etiologies of dislocation in this case were investigated by erythrocyte sedimentation rate (ESR), C-reactive protein (CRP), tissue culture, plain radiograph, and CT scan. The infection was ruled out because of normal ESR, CRP, and negative intraoperative bacterial culture. The center-edge (CE) angle was $20^{\circ}$ and the acetabular angle of shape was $49^{\circ}$. The author concluded that the reason for dislocation was missed diagnosis of the adult dysplasia of the hip (DDH), which was probably best managed by THA instead of BHA (Figure 5). This patient was treated by open reduction after failed closed reduction, exchange to longer femoral head, and postoperative abduction casting for 4 weeks. There was no recurrent dislocation at 1 year. According to Kim et al, ${ }^{37}$ the risk of dislocation after BHA was 5.3 times higher in the $\mathrm{CE}$ angle $<44^{\circ}$. The small $\mathrm{CE}$ angle indicates shallow acetabulum and results in inadequate acetabular coverage after BHA. They recommend careful monitoring in patients with smaller $\mathrm{CE}$ angle. However, if the missed-diagnosis DDH case was excluded, there was no operative hip dislocation in the study. This was lower than what had been described, $7.6 \%-17.2 \%$, in the meta-analysis. ${ }^{38-40}$

There are several limitations in the present study. First, this study was the case series without the comparison group. Secondly, the hand-held dynamometer was not the best method to evaluate the muscle power. However, there

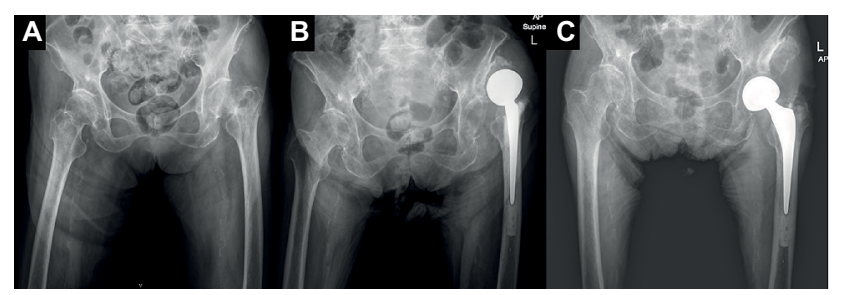

Figure 5 Demonstrates the missed-diagnosis dysplasia of the hip.

Notes: The center-edge angle was $20^{\circ}$ and the acetabular angle of shape was $49^{\circ}$ (A). The anterior hip dislocation was found at second week follow-up (B). This patient was treated by open reduction and exchange to longer femoral head offset. Abduction cast was applied for 4 weeks. There was no recurrent dislocation at I year (C). 
were literatures that described the acceptable accuracy and reliability of the hand-held dynamometer. ${ }^{41,42}$ Finally, the follow-up was only 6 months. This study did not reflect the long-term hip muscular strength, functional hip score, and 1 year mortality rate in the osteoporotic hip fractures, which underwent muscle-sparing approach.

\section{Conclusion}

The ABMS had benefits in terms of faster hip muscle strength recovery and earlier postoperative mobilization in the first 3 months without iatrogenic femoral cutaneous nerve injury. The ABMS-related complications significantly related to the learning skill (first 11 cases). The adequate posterior soft tissue release and gentle manipulation of the hip joint play important roles for IFF prevention. BHA might relate to higher IFF because of difficult reduction from large femoral head diameter. The trial femoral stem evaluation under fluoroscope without putting in the trial bipolar head was recommended.

\section{Disclosure}

The authors report no conflicts of interest in this work.

\section{References}

1. Johnell O, Kanis JA. An estimate of the worldwide prevalence and disability associated with osteoporotic fractures. Osteoporos Int. 2006;17(12):1726-1733.

2. Clayer MT, Bauze RJ. Morbidity and mortality following fractures of the femoral neck and trochanteric region: analysis of risk factors. $J$ Trauma. 1989;29(12):1673-1678.

3. Siebert HR, Beck A. Trauma surgery in the elderly. Chirurg. 2005;76(2):139-150.

4. Becker C, Gebhard F, Fleischer S, et al. Prediction of mortality, mobility and admission to long-term care after hip fractures. Unfallchirurg. 2003;106(1):32-38.

5. Higgins BT, Barlow DR, Heagerty NE, Lin TJ. Anterior vs. posterior approach for total hip arthroplasty, a systematic review and metaanalysis. J Arthroplasty. 2015;30(3):419-434.

6. Mayr E, Nogler M, Benedetti MG, et al. A prospective randomized assessment of earlier functional recovery in THA patients treated by minimally invasive direct anterior approach: a gait analysis study. Clin Biomech (Bristol, Avon). 2009;24(10):812-818.

7. Lamontagne M, Varin D, Beaule PE. Does the anterior approach for total hip arthroplasty better restore stair climbing gait mechanics? $J$ Orthop Res. 2011;29(9):1412-1417.

8. Klausmeier V, Lugade V, Jewett BA, Collis DK, Chou LS. Is there faster recovery with an anterior or anterolateral THA? A pilot study. Clin Orthop Relat Res. 2010;468(2):533-541.

9. Reardon K, Galea M, Dennett X, Choong P, Byrne E. Quadriceps muscle wasting persists 5 months after total hip arthroplasty for osteoarthritis of the hip: a pilot study. Intern Med J. 2001;31(1):7-14.

10. Bertocci GE, Munin MC, Frost KL, Burdett R, Wassinger CA, Fitzgerald SG. Isokinetic performance after total hip replacement. Am J Phys Med Rehabil. 2004;83(1):1-9.

11. Sicard-Rosenbaum L, Light KE, Behrman AL. Gait, lower extremity strength, and self-assessed mobility after hip arthroplasty. $J$ Gerontol A Biol Sci Med Sci. 2002;57(1):M47-M51.
12. Winther SB, Husby VS, Foss OA, et al. Muscular strength after total hip arthroplasty. A prospective comparison of 3 surgical approaches. Acta Orthop. 2016;87(1):22-28.

13. Judd DL, Dennis DA, Thomas AC, Wolfe P, Dayton MR, StevensLapsley JE. Muscle strength and functional recovery during the first year after THA. Clin Orthop Relat Res. 2014;472(2):654-664.

14. Podsiadlo D, Richardson S. The timed "Up \& Go": a test of basic functional mobility for frail elderly persons. J Am Geriatr Soc. 1991;39(2):142-148.

15. Meermans G, Malik A, Witt J, Haddad F. Preoperative radiographic assessment of limb-length discrepancy in total hip arthroplasty. Clin Orthop Relat Res. 2011;469(6):1677-1682.

16. Brooker AF, Bowerman JW, Robinson RA, Riley LH Jr. Ectopic ossification following total hip replacement. Incidence and a method of classification. J Bone Joint Surg Am. 1973;55(8):1629-1632.

17. Jewett BA, Collis DK. High complication rate with anterior total hip arthroplasties on a fracture table. Clin Orthop Relat Res. 2011;469(2):503-507.

18. Rachbauer F. Minimally invasive total hip arthroplasty via direct anterior approach. Orthopade. 2005;34(11):1103-1104, 1106-1108, 1110.

19. Barton C, Kim PR. Complications of the direct anterior approach for total hip arthroplasty. Orthop Clin North Am. 2009;40(3):371-375.

20. Howell JR, Garbuz DS, Duncan CP. Minimally invasive hip replacement: rationale, applied anatomy, and instrumentation. Orthop Clin North Am. 2004;35(2):107-118.

21. Spaans AJ, van den Hout JA, Bolder SB. High complication rate in the early experience of minimally invasive total hip arthroplasty by the direct anterior approach. Acta Orthop. 2012;83(4):342-346.

22. Nakai T, Liu N, Fudo K, Mohri T, Kakiuchi M. Early complications of primary total hip arthroplasty in the supine position with a modified Watson-Jones anterolateral approach. J Orthop. 2014;11(4):166-169.

23. Rudiger HA, Betz M, Zingg PO, McManus J, Dora CF. Outcome after proximal femoral fractures during primary total hip replacement by the direct anterior approach. Arch Orthop Trauma Surg. 2013;133(4):569-573.

24. Post ZD, Orozco F, Diaz-Ledezma C, Hozack WJ, Ong A. Direct anterior approach for total hip arthroplasty: indications, technique, and results. J Am Acad Orthop Surg. 2014;22(9):595-603.

25. Beck M, Sledge JB, Gautier E, Dora CF, Ganz R. The anatomy and function of the gluteus minimus muscle. J Bone Joint Surg Br. 2000;82(3):358-363.

26. Amanatullah DF, Masini MA, Roger DJ, Pagnano MW. Greater inadvertent muscle damage in direct anterior approach when compared with the direct superior approach for total hip arthroplasty. Bone Joint J. 2016;98-B(8):1036-1042.

27. Wani IH, Sharma S, Latoo I, Salaria AQ, Farooq M, Jan M. Primary total hip arthroplasty versus internal fixation in displaced fracture of femoral neck in sexa- and septuagenarians. $J$ Orthop Traumatol. 2014;15(3):209-214.

28. Park KS, Oh CS, Yoon TR. Comparison of minimally invasive total hip arthroplasty versus conventional hemiarthroplasty for displaced femoral neck fractures in active elderly patients. Chonnam Med J.2013; 49(2):81-86.

29. Macaulay W, Nellans KW, Iorio R, et al. Total hip arthroplasty is less painful at 12 months compared with hemiarthroplasty in treatment of displaced femoral neck fracture. HSS J. 2008;4(1):48-54.

30. van den Bekerom MP, Hilverdink EF, Sierevelt IN, et al. A comparison of hemiarthroplasty with total hip replacement for displaced intracapsular fracture of the femoral neck: a randomised controlled multicentre trial in patients aged 70 years and over. J Bone Joint Surg Br. 2010;92(10):1422-1428.

31. Blomfeldt R, Tornkvist H, Eriksson K, Soderqvist A, Ponzer S, Tidermark J. A randomised controlled trial comparing bipolar hemiarthroplasty with total hip replacement for displaced intracapsular fractures of the femoral neck in elderly patients. J Bone Joint Surg Br. 2007;89(2):160-165.

32. Mouzopoulos G, Stamatakos M, Arabatzi H, et al. The four-year functional result after a displaced subcapital hip fracture treated with three different surgical options. Int Orthop. 2008;32(3):367-373. 
33. Hartford JM, Bellino MJ. The learning curve for the direct anterior approach for total hip arthroplasty: a single surgeon's first 500 cases. Hip Int. 2017;27(5):483-488.

34. de Steiger RN, Lorimer M, Solomon M. What is the learning curve for the anterior approach for total hip arthroplasty? Clin Orthop Relat Res. 2015;473(12):3860-3866.

35. Woolson ST, Pouliot MA, Huddleston JI. Primary total hip arthroplasty using an anterior approach and a fracture table: short-term results from a community hospital. J Arthroplasty. 2009;24(7):999-1005.

36. Cohen EM, Vaughn JJ, Ritterman SA, Eisenson DL, Rubin LE. Intraoperative femur fracture risk during primary direct anterior approach cementless total hip arthroplasty with and without a fracture table. J Arthroplasty. 2017;32(9):2847-2851.

37. Kim Y, Kim JK, Joo IH, Hwang KT, Kim YH. Risk factors associated with dislocation after bipolar hemiarthroplasty in elderly patients with femoral neck fracture. Hip Pelvis. 2016;28(2):104-111.
38. Zi-Sheng A, You-Shui G, Zhi-Zhen J, Ting Y, Chang-Qing Z. Hemiarthroplasty vs. primary total hip arthroplasty for displaced fractures of the femoral neck in the elderly: a meta-analysis. J Arthroplasty. 2012;27(4):583-590.

39. Yu L, Wang Y, Chen J. Total hip arthroplasty versus hemiarthroplasty for displaced femoral neck fractures: meta-analysis of randomized trials. Clin Orthop Relat Res. 2012;470(8):2235-2243.

40. Burgers PT, Van Geene AR, Van den Bekerom MP, et al. Total hip arthroplasty versus hemiarthroplasty for displaced femoral neck fractures in the healthy elderly: a meta-analysis and systematic review of randomized trials. Int Orthop. 2012;36(8):1549-1560.

41. Thorborg K, Petersen J, Magnusson SP, Holmich P. Clinical assessment of hip strength using a hand-held dynamometer is reliable. Scand J Med Sci Sports. 2010;20(3):493-501.

42. Krause DA, Neuger MD, Lambert KA, Johnson AE, DeVinny HA, HolIman JH. Effects of examiner strength on reliability of hip-strength testing using a handheld dynamometer. J Sport Rehabil. 2014;23(1):56-64.
Orthopedic Research and Reviews

\section{Publish your work in this journal}

Orthopedic Research and Reviews is an international, peer-reviewed, open access journal that focusing on the patho-physiology of the musculoskeletal system, trauma, surgery and other corrective interventions to restore mobility and function. Advances in new technologies, materials, techniques and pharmacological agents are particularly

\section{Dovepress}

welcome. The manuscript management system is completely online and includes a very quick and fair peer-review system, which is all easy to use. Visit http://www.dovepress.com/testimonials.php to read real quotes from published authors. 